\title{
Product Planning and Development of Bucket Type Strainer Used In Thermal Power Plant
}

\author{
Mr. Pushpdant Jain ${ }^{1}$, Mr. Prabhash Jain ${ }^{2}$ \\ ${ }^{I}$ (Department of Mechanical Engineering, Barkatullah University Institute of Technology Bhopal, India) \\ ${ }^{2}$ (HOD, Department of Mechanical Engineering, Barkatullah University Institute of Technology Bhopal, India)
}

\begin{abstract}
A New Product Introduction and Development process is one of the Corner stone's towards a competitive advantage in any market place today. A fully optimised process in combination with other lean and agile manufacturing techniques and systems is guaranteed to reduce lead-time and save on cost. New product development is a means for a company to gain advantage, secure a position, or win a new customer. The more successful and timely an organization can develop new products, the more likely it is that organization will not only survive but prosper.

${ }^{(2)}$ As suggested by review of the literature's and studies, there are several factors that significantly affect a product's chances of succeeding or failing. Many of these factors are associated with resources resulting from marketing activities that integrate the user/customer needs into the process. There is a significant amount of research that indicates that

Conducting early stage marketing activities greatly improves the likelihood of new product success, yet the deficiency of these activities is one of the most commonly stated reasons for product failure by New Product Development members.
\end{abstract}

\section{Introduction}

This paper is a detailed examination of the common factors of new product planning, design \& development i.e. Bucket type strainer. It also states about the process involved for manufacturing \& establishes criteria for new product success, the market research tools available for integrating the user/customer needs into the innovative process. The examination of these topics results in the development of an enhanced innovative process model.

Development of new products is extremely essential for the success and smooth running of every industry. There is ample scope of cost saving in various products of every industry. Planning \& development of a new product also involved success or failure of systems associated with it. Here we are going to analyse all aspect with respect to need, planning, information collection \& analysis, implementation of data's collected and finally development.

\subsection{ABOUT THE PRODUCT (BUCKET TYPE STRAINER)}

${ }^{(2)}$ Water lines systems can get gravel, deposits that break free, and other stray items in the line. The velocity of the water pushing them, they can severely damage or clog devices installed in the flow stream of the water line. A strainer is essentially a screen installed to allow liquids to pass through in it. Strainers are used primarily to catch very large as well as small particles and will be found in applications where this type of protection is required. The larger items fall to the bottom or are held in a basket for later clean out. They normally have an access that allows for them to be cleaned or have the strainer plate or basket replaced. Most hydraulic systems have a strainer in the reservoir at the inlet to the suction line of the pump. A strainer is used in lieu of a filler to reduce its chance of being clogged and starving the Pump. However since the strainer located very near to reservoir its maintenance is frequently neglected. When heavy dirt and sludge accumulate on the suction side of strainer the pump soon begins to cavitate. Pump failure follows quickly.

\section{${ }^{(1)}$ Type of strainers}

1. Y-Type strainers

2. T-Type strainers

3. Conical Type strainers

4. Bucket Type strainers

5. Duplex Type strainers

${ }^{(2)}$ Strainers come in several different styles as mentioned above based on the needs \& application requirement. A plate strainer is the simplest, in which water flows through a perforated plate. Often the plate is corrugated shape to increase surface area. A basket strainer is a design where the strainer is shaped like a basket and usually installed in a vertical cylinder and horizontal/ vertical pipes. The basket strainer is easier to clean, 
since debris is captured in the basket. It can also sometimes offer more straining surface area than a plate strainer, improving flow rates, or decreasing pressure loss through the strainer. Strainer elements are generally selected as per the application and for water /condensate application it is better to have it from stainless steel for corrosion resistance.

\subsection{ABOUT THE COMPANY}

${ }^{(3)}$ GEI Industrial Systems Ltd was established in the year 1970 in the city of Bhopal in the Central Indian State of Madhya Pradesh. GEI Industrial Systems Ltd is a leader in heat transfer technology for more than 40 years and specializes in the design, manufacture, fabrication, testing, and erection \& commissioning of Air Cooled Heat Exchangers for Oil, Gas and Power sector and Air Cooled Vacuum Steam Condensers for Steam Turbine Power Plants. GEI is an ISO 9001-2008 certified company and follow Quality Management Systems for the entire business process right from the basic design to manufacturing and installation at the site. GEI holds U stamp certification; The National Board of Boilers and Pressure Vessel Inspector have provided R stamp certification and NB Marking. More than 4000 bundles of Air Cooled Heat Exchanger and Air Cooled Steam Condenser are operating in India and abroad in the oil, gas and power sector in more than 18 countries worldwide. GEI heat transfer products are operating across the globe in the regions of Africa, Americas, Asia, Europe and Oceania. GEI is today one of the leading Engineering and Manufacturing Company dealing with heat transfer equipments with a major thrust in Air Cooled Heat Exchangers and Air Cooled Steam Condensers. The Air Cooled Heat Exchangers are used for cooling of hot fluids using atmospheric air in the Oil and Gas Exploration, Production, Refining and Petrochemical Industry and also in the power plants as dry cooling tower as a replacement of conventional wet type cooling towers.

Air Cooled Vacuum Steam Condensers are revolutionary product being used in steam turbine power plants thereby eliminating Water Cooled Steam Condenser and Cooling Towers which consumes lot of water.

${ }^{(3)}$ GEI has a total factory area of about 34.5 acres spread at two locations namely in Govindpura and Mandideep near Bhopal. The total manpower strength of GEI is 650 which include qualified professional and experience workmen trained in various disciplines right from Basic Design, Detailed Design and Engineering, Procurement, Project Monitoring, Production Planning, Manufacturing, Quality Control, Logistics, Site Services and support functional like Finance, HR, Safety and Maintenance.

Heat transfer products designed manufactured and supplied by GEI have been installed at different locations around the Globe and are performing satisfactory at different locations in Africa, Europe, Middle East, South East and Far East Asian countries and in the Americas.

\subsection{PRODUCTS LINE OF THE COMPANY}

${ }^{(3)}$ GEI specializes in heat transfer technology and has an excellent track record in Design \& Manufacturing of following

\section{* AIR COOLED HEAT EXCHANGERS for}

- OIL - Exploration, Refining, \& Petrochemicals -GAS - Exploration, Production, Processing, Compression, Re-gasification, Transportation \& Utility -POWER - Thermal, Nuclear, Gas, Hydro, Solar \& Biomass Plants

* AIR COOLED STEAM CONDENSERS for Thermal Power Plants and Combined Cycle Power Plants.

* GLAND STEAM CONDENSERS for Thermal Power plants.

* DE-AERATORS for Thermal Power plants.

* Bucket type Strainers are not currently in the product list of GEI and with the help of this dissertation it will come in standard product List.

\section{Research Method}

Research methods basically consist of two phases

1. Design Phase

2. Results Phase

Design Phase basically the detailed engineering and design phase which involves the detailed product planning process then after implementation of the same we will process to development phase. Details of each phase shall be discussed in detailed here. 
3.1 The Product Planning Process / Design Phase ${ }^{(4)}$

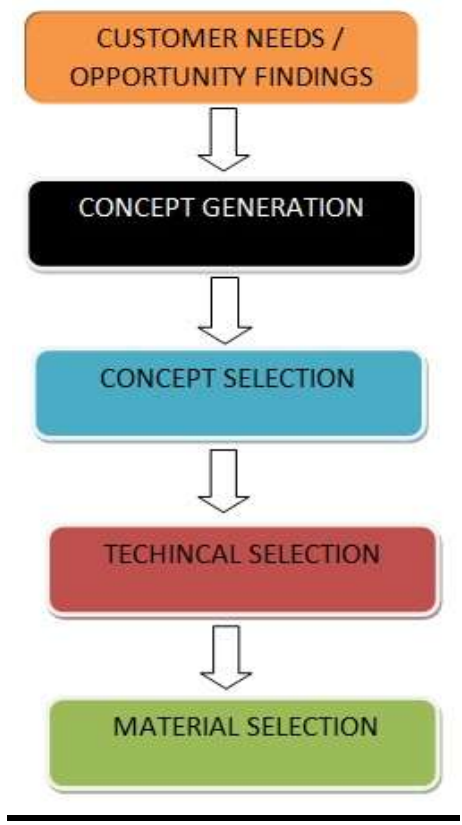

\subsubsection{CUSTOMER NEEDS / OPPORTUNITY FINDINGS}

As GEI is using the Bucket type Strainer in their Air Cooled Steam Condenser Plant Application in Thermal power plant, here client is themselves only. Apart from self using, for increasing the product sales they can also sale the Bucket type strainer in market for other clients.

(1)

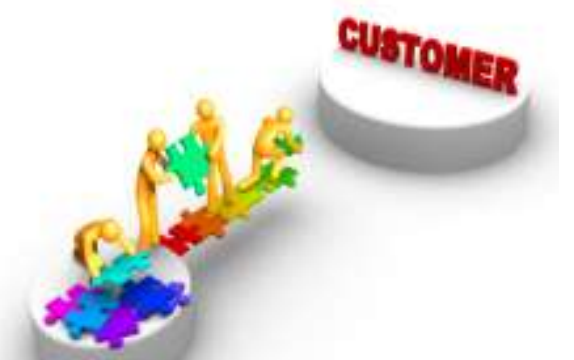

(5)"You cannot manage a quality service organization unless you understand the nature of what you are providing; fully realize what your customers want from you and how they perceive you from the start."

W. Martin: Managing Customer Service, Crisp, 1989

Once you have identified who your customers are, you need to assess what they need from your product or service.

Most customer needs can be divided into four basic categories:

- The need to be understood.

Customers need to feel that the message they are sending is being correctly received and interpreted.

- The need to feel welcome

Customers need to feel that you are happy to see them.

- The need to feel important.

Customers like to feel important and special.

- The need for comfort.

Customers need physical and psychological comfort.

\subsubsection{The Value of Knowing Customers}

(11) By knowing who your customers are, you are more able to meet their needs. 
Radio stations and television stations conduct regular market research to find out who their listeners and viewers are and often adapt their programs to suit the audience. Radio stations particularly have become niche service providers as they specifically aim their product at a particular group, or niche.

Think about the following questions in relation to your team (or company).

- What is your service niche?

- What are the characteristics of the service/s you provide?

- Who are your clients and what do they want?

\subsubsection{The Rater Model}

${ }^{(5)}$ There are a number of different ways of categorising what customers want and value. One of these is called the RATER Model. This is made up of five elements:

\section{- Reliability}

"Do what you say you will do, reliably and consistently"

Relates to timeliness, consistency, regularity, accuracy.

\section{- $\quad$ Assurance}

"I need to be confident of the knowledge and courtesy of your staff"

Relates to competence, knowledge, respect, credibility, honesty, confidentiality, safety, security.

\section{- $\quad$ Tangibles}

"Make sure your facilities, equipment, communication materials look attractive and are user friendly"

Relates to appearance of facilities, staff, and communication facilities.

\section{- $\quad$ Empathy}

"Treat me as an individual, in a caring and empathic way; understand my needs" Relates to access to staff and information, clear, appropriate and timely information, individualised attention.

\section{- Responsiveness}

"Be flexible and willing to help me; resolve my problems promptly and effectively" Relates to prompt service

\subsection{CONCEPT GENERATION \& SELECTION}

Innovation is now recognized as the single most important ingredient in any modern economy. - The Economist ${ }^{(6)}$ Concept generation, getting the ideas, begins with ideation and brainstorming. There are three things to work with - facts, ideas, and solutions; each deserves quality time. The natural tendency is to leap from facts to solutions, skipping over the play and exploration, which is at the heart of finding new ideas. Most of us are experienced with fact finding, it's a consequence of contemporary education's preoccupation with facts. We're also familiar with solutions; most of us like to solve problems and move on. Idea finding may seem childlike (and it should be) but at its heart is the exploration of possibilities, free from as many constraints as possible.

Brainstorming is not new-age nonsense, rather it is a studied process and practiced art for suspending judgment, encouraging wild ideas, and building upon those ideas to invent something that has value. If nothing revolutionary, weird, or goofy surfaces, this stage has failed. The vibe should be upbeat - a chance to try things out, to free associate, and to challenge the wisdom of the present.

With respect to Bucket type strainers concept is fixed but we have to make the brainstorming over its design, method for calculations, sizing etc. The above said processed involved following steps.

1. Determined customer requirement for your design.

2. Determined importance / weighting factors for these requirements

3. Determined how the concept can be conveyed

4. Establish a strong base case concept / guidelines.

5. Generate many concepts.

6. Evaluate the concepts.

7. Identify the best options.

8. Try to provide hybrid solutions i.e. Butt welded arrangement / flanged arrangement.

9. Select a robust concept and move forward 


\subsection{TECHNICAL SELECTION OF BUCKET TYPE STRAINER}

Selecting the right techniques / process to incorporate in new products is a particularly challenging aspect of new product definition and development. While newer advanced technologies may offer improved performance, they also make the product development process more risky and challenging. In this paper, we focus on the technical selection and commitment. For technical selection following process shall be followed.

1. Pressure drop calculation.

2. Material Selection.

\subsubsection{PRESSURE DROP CALCULATION}

Here we have presented a sample calculation of pressure drop across wire mesh (item no. 3) of Strainer of $80 \mathrm{NB}$ diameter.

Importance of Pressure drop calculation.

1. Pressure drop calculation is useful to select the Pump head for suitable selection.

2. It is necessary for identifying the set values of other instruments like differential pressure switch installed across the bucket type strainers.

3. Frequency \& nature of debris creates clogging will indicate the type of problem associated with upstream system.

4. Screen replacement at designed time interval.

5. For setting of proper Inter logics between instruments of plant.

6. If pressure drop value is more than specified then it will calls for cleaning of strainer.

7. Mesh selection should be such that the size of particle coming to it should not larger than the gap between impeller and casing.

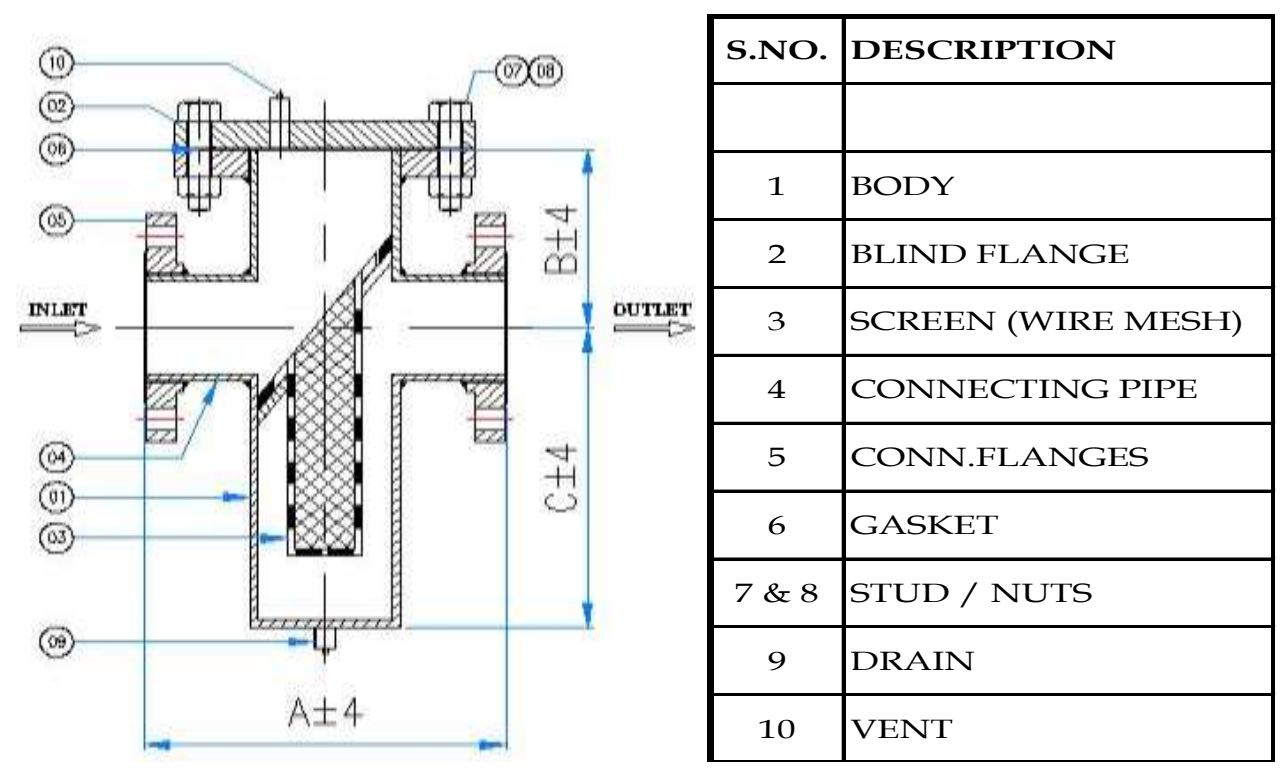

\begin{tabular}{|c|c|c|c|c|c|}
\hline \multicolumn{6}{|c|}{$\begin{array}{l}\text { PRESSURE DROP CALCULATION FOR 80NB DIA STRAINER } \\
\text { PTION }\end{array}$} \\
\hline IN PUT & & & & \\
\hline PIPE Dia. & \multicolumn{3}{|l|}{ D } & 88.9 & \multirow{2}{*}{$\begin{array}{l}\mathrm{mm} \\
\mathrm{mm}\end{array}$} \\
\hline Length of Screened pipe & $\mathbf{L}$ & & & 240.0 & \\
\hline \multirow{5}{*}{$\begin{array}{l}\text { Thickness of wire mesh } \\
\text { Dia. of hole in wire mesh } \\
\text { Vertical pitch } \\
\text { Horizontal pitch } \\
\text { Flow rate }\end{array}$} & \multicolumn{3}{|l|}{ I } & 0.1 & \multirow{5}{*}{$\begin{array}{l}\mathrm{mm} \\
\mathrm{mm} \\
\mathrm{mm} \\
\mathrm{mm} \\
\mathrm{Kg} / \mathrm{hrs}\end{array}$} \\
\hline & $\mathbf{D}_{\mathrm{h}}$ & & & 0.3000 & \\
\hline & \multicolumn{3}{|l|}{$\mathbf{s}$} & 0.3000 & \\
\hline & \multirow{2}{*}{\multicolumn{3}{|c|}{$\mathbf{Q}$}} & 0.3000 & \\
\hline & & & & 30000.0 & \\
\hline \multicolumn{6}{|l|}{ OUT PUT } \\
\hline $\begin{array}{l}\text { Cross sectional area of } \\
\text { screened pipe }\end{array}$ & A & $=Л \times \mathrm{D} 2 / 4$ & $=$ & 6207.2 & $\mathrm{~mm}^{2}$ \\
\hline Velocity of condensate & $\mathbf{v}$ & $=\omega / \mathrm{A}$ & $=$ & 1.343 & $\mathrm{~m} / \mathrm{sec}$ \\
\hline
\end{tabular}


Orifice constant

Circumference of pipe

No of hole (column) $\left(\mathrm{N}_{\mathrm{c}}\right)$

No of hole(row) $\left(\mathrm{N}_{\mathrm{r}}\right)$

Total no holes in Screen

Total area of perforated

holes

Percentage of open area

Specific weight of

condensate water k1 From table A

$=\left\{\left(1-\left(\mathrm{A}_{\mathrm{r}} / 100\right)^{2}\right) /\left(\mathrm{k}_{1}-\right.\right.$

C $\left.\left.\left(\mathrm{A}_{\mathrm{r}} / 100\right)^{2}\right)\right\}^{1 / 2}$

Cir

$\mathbf{N}_{\mathbf{c}}=$ cir $/ \mathrm{s}-1$

$\mathbf{N}=\left(\mathrm{N}_{\mathrm{c}} \times \mathrm{N}_{\mathrm{r}}\right)$

$\begin{array}{ll}\mathbf{A}_{\mathbf{0}} & =\mathrm{N} \text { х л х } \mathrm{D}_{\mathrm{h}}{ }^{2} / 4 \\ \mathbf{A}_{\mathrm{r}} & =100 *\left(0.785^{*} \mathrm{D}_{\mathrm{h}}{ }^{2}\right) / \mathrm{S}_{1} \mathrm{XS}_{2}\end{array}$

r- $=$
$\mathbf{N}_{\mathbf{r}}=\mathrm{L} / \mathrm{s}+1$

$=$

(1)

0.9

$=279.3 \mathrm{~mm}$

$=200.0$ Nos.

$=100.0$ Nos.

$=20000.0$ Nos.

$=$

$0.0014 \mathrm{~m}^{2}$

$78.5 \%$

$9731.0 \mathrm{~N} / \mathrm{m}^{3}$

Available pressure drop as per calculation

$=$

$4546 \mathrm{~N} / \mathrm{m}^{2}$

Available pressure drop as per calculation

(7)

Values of resistance Co-efficient $\mathrm{K1}^{(7)}$

\begin{tabular}{|c|c|c|c|c|c|c|c|c|c|c|c|c|c|c|c|c|c|c|}
\hline $\begin{array}{l}\text { S. } \\
\text { NO. }\end{array}$ & 1 & 2 & 3 & 4 & 5 & 6 & 7 & 8 & 9 & 10 & 11 & 12 & 13 & 14 & 15 & 16 & 17 & 18 \\
\hline & \multicolumn{18}{|c|}{$\mathrm{Ar} / 100$} \\
\hline & L/Dh & 0 & 0.02 & 0.04 & 0.06 & 0.08 & 0.1 & 0.15 & 0.2 & 0.25 & 0.3 & 0.4 & 0.5 & 0.6 & 0.7 & 0.8 & 0.9 & 1 \\
\hline 1 & 0 & 0.2 & 7000 & 1670 & 730 & 400 & 245 & 96 & 51.5 & 30 & 18.2 & 8.25 & 4 & 2 & 0.97 & 0.42 & 0.13 & 0 \\
\hline 2 & 0.2 & 0.4 & 6600 & 1600 & 687 & 374 & 230 & 94 & 48 & 28 & 17.4 & 7.7 & 3.75 & 1.87 & 0.91 & 0.4 & 0.13 & 0.01 \\
\hline 3 & 0.4 & 0.6 & 6310 & 1530 & 660 & 356 & 221 & 89 & 46 & 26.5 & 16.6 & 7.4 & 3.6 & 1.8 & 0.88 & 0.39 & 0.13 & 0.01 \\
\hline 4 & 0.6 & 0.8 & 5700 & 1380 & 590 & 322 & 199 & 81 & 42 & 24 & 15 & 6.6 & 3.2 & 1.6 & 0.8 & 0.36 & 0.13 & 0.01 \\
\hline 5 & 0.8 & 1 & 4680 & 1130 & 486 & 264 & 164 & 66 & 34 & 19.6 & 12.2 & 5.5 & 2.7 & 1.34 & 0.66 & 0.31 & 0.12 & 0.02 \\
\hline 6 & 1 & 1.4 & 4260 & 1030 & 443 & 240 & 149 & 60 & 31 & 17.8 & 11.1 & 5 & 2.4 & 1.2 & 0.61 & 0.29 & 0.11 & 0.02 \\
\hline 7 & 1.4 & 2 & 3930 & 950 & 408 & 221 & 137 & 55.6 & 28.4 & 16.4 & 10.3 & 4.6 & 2.25 & 1.15 & 0.58 & 0.28 & 0.11 & 0.03 \\
\hline 8 & 2 & 3 & 3770 & 910 & 391 & 212 & 134 & 53 & 27.4 & 15.8 & 9.9 & 4.4 & 2.2 & 1.13 & 0.58 & 0.28 & 0.12 & 0.04 \\
\hline 9 & 3 & 4 & 3765 & 913 & 392 & 214 & 132 & 53.5 & 27.5 & 15.9 & 10 & 4.5 & 2.24 & 1.17 & 0.61 & 0.31 & 0.15 & 0.06 \\
\hline 10 & 4 & 5 & 3775 & 930 & 400 & 215 & 132 & 53.8 & 27.7 & 16.2 & 10 & 4.6 & 2.25 & 1.2 & 0.64 & 0.35 & 0.16 & 0.08 \\
\hline 11 & 5 & 6 & 3850 & 936 & 400 & 220 & 133 & 55.5 & 28.5 & 16.5 & 10.5 & 4.75 & 2.4 & 1.28 & 0.69 & 0.37 & 0.19 & 0.1 \\
\hline 12 & 6 & 7 & 3870 & 940 & 400 & 222 & 133 & 55.8 & 28.5 & 16.6 & 10.5 & 4.8 & 2.42 & 1.32 & 0.7 & 0.4 & 0.21 & 0.12 \\
\hline 13 & 7 & 8 & 4000 & 950 & 405 & 230 & 135 & 55.9 & 29 & 17 & 10.9 & 5 & 2.5 & 1.38 & 0.74 & 0.43 & 0.23 & 0.14 \\
\hline
\end{tabular}

\subsection{MATERIAL SELECTION}

Material selection is a step in the process of designing any physical object. In the context of product design, the main goal of material selection is to minimize cost while meeting product performance goals. Systematic selection of the best material for a given application begins with properties and costs of candidate materials.

As far as concerns with the Bucket type strainer and application to power plant, we have considered the material as per standard practice; we can also change the material as per the other application and client requirement. The whole basis of material selection process is directly related to following.

1. Application of the product.

2. As per the codes and Standards

3. Cost associated with the product

4. Market competition

5. Availability of materials.

Selected materials details are described in next section of results \& conclusion phase. 


\section{Result \& Conclusion}

Development phase involves the sizing of the strainer, which is done as per the Manufacturing standards and tolerance and selection of materials shall be done as per ASME B 16.5 (2009) ANSI B 36.10 and as per ASME SEC VIII (2010).

\section{Conclusion:}

With the above sizing and calculations manufacturing of the below bucket type strainer can be done and same shall be used in process refineries and power plants for equipment safety, which are installed downstream to strainer.

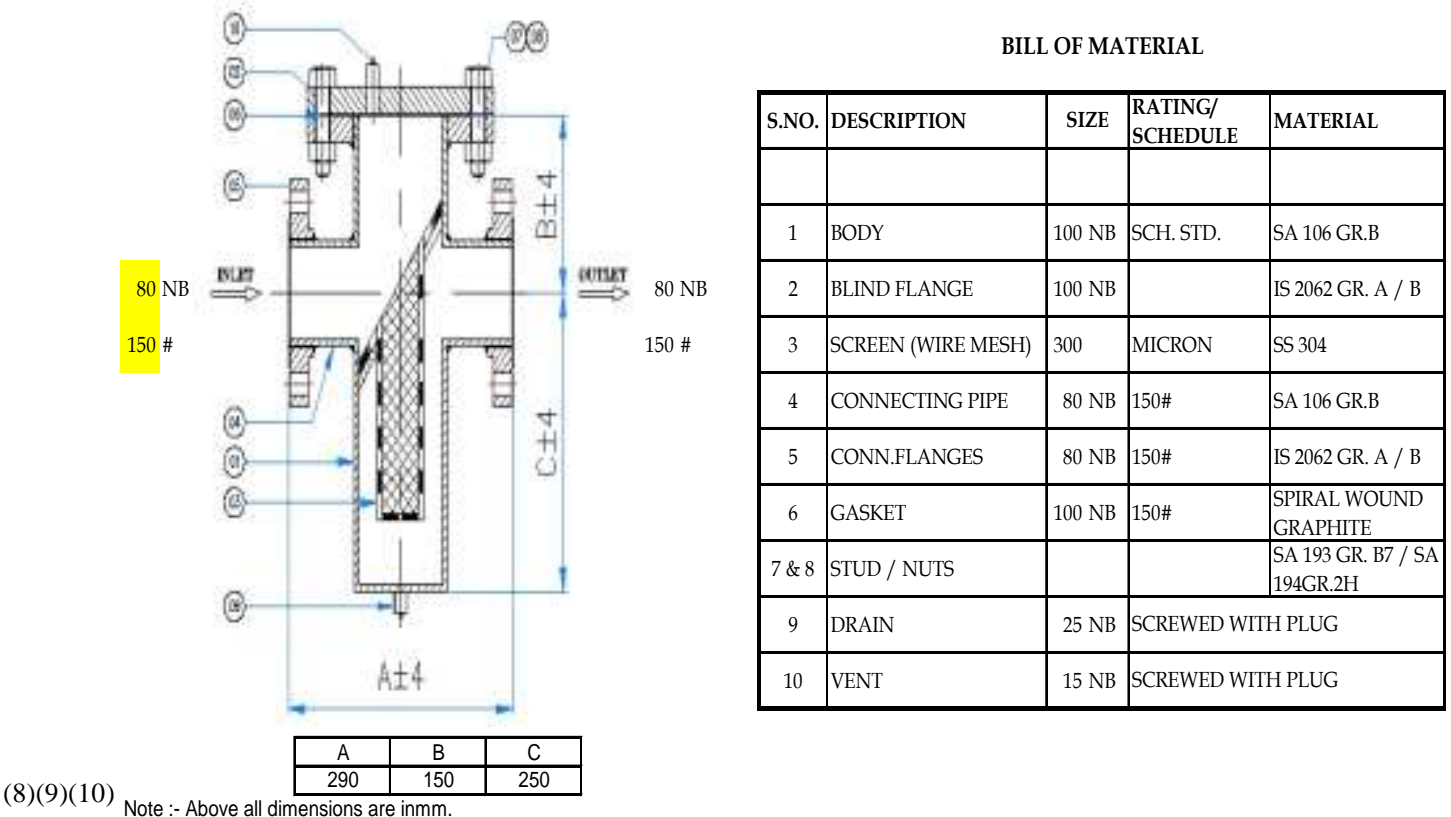

\section{Acknowledgements}

The author would like to thank AGM Mr. Jackson Fernandez (GEI Industrial Systems Limited, Bhopal) and his team members Rakesh Malviya, Abhishek Malviya, Varghese Abraham \& Nishant Agnihotri for their valuable comments and suggestions. This research was supported by GEI Industrial Systems Limited, Bhopal M.P. India.

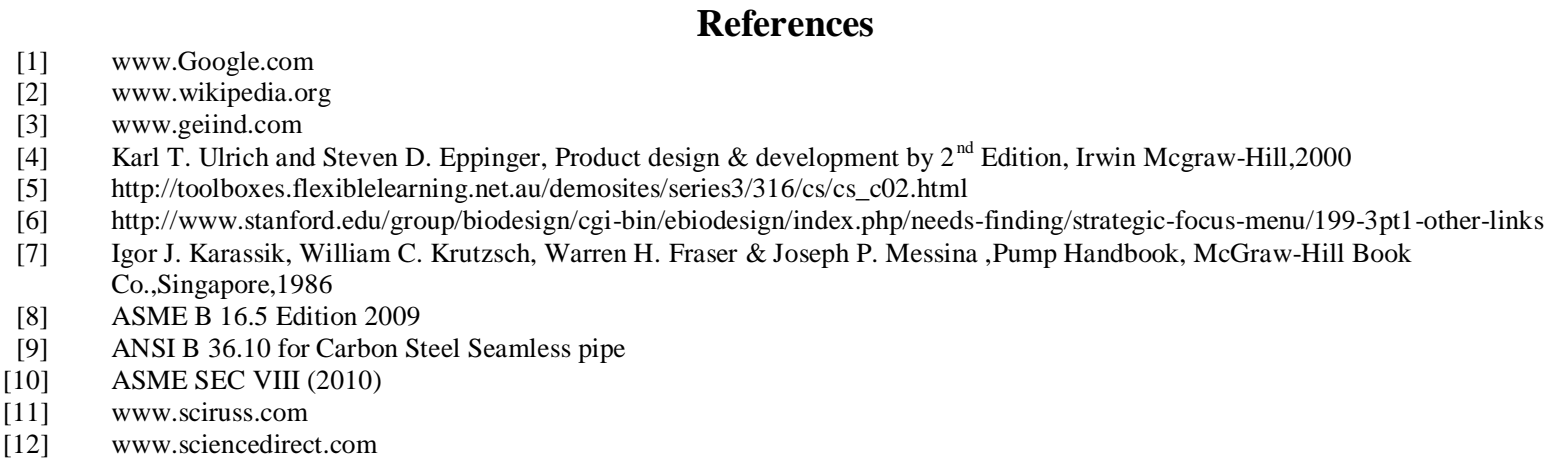

